\title{
Isolation and identification of Bifidobacterium species from feces of captive chimpanzees
}

\author{
Ryohei NOMOTO ${ }^{1,2}$, Shintaro TAKANO ${ }^{1}$, Kosei TANAKA², Yuji TSUJIKAWA ${ }^{1}$, Hiroshi KUSUNOKI ${ }^{1}$ and \\ Ro OSAWA ${ }^{1,2^{*}}$ \\ ${ }^{1}$ Department of Bioresource Science, Organization of Advanced Science and Technology, Kobe University, 1-1 Rokko-dai, Nada-ku, \\ Kobe 657-8501, Japan \\ ${ }^{2}$ Health Bioscience Team, Organization of Advanced Science and Technology, Kobe University, 1-1 Rokko-dai, Nada-ku, \\ Kobe 657-8501, Japan
}

Received November 18, 2016; Accepted March 8, 2017; Published online in J-STAGE April 3, 2017

Recently, gut-dwelling bifidobacteria from chimpanzees, which are phylogenetically close to humans and have feeding habits similar to humans, have been frequently investigated. Given this, we speculated that like humans, chimpanzees would have a unique diversity of bifidobacteria. We herein describe a taxonomically novel member of bifidobacteria isolated from fecal samples of captive chimpanzees. Bifidobacteria were detected in all fecal samples by quantitative polymerase chain reaction. A Bifidobacterium pseudolongum-like species, which could not be detected using $B$. pseudolongum-specific primers targeting the groEL gene sequence, was dominant in the feces of five chimpanzees. Seven bifidobacterial strains were isolated from this group of five chimpanzees, and all isolates were identified as B. pseudolongum. B. pseudolongum has previously often been isolated from non-primate animals as well as humans; however, here we demonstrate its presence in a nonhuman primate species.

Key words: Bifidobacterium pseudolongum, chimpanzee feces, 16S rRNA gene sequence, clone library, groEL gene sequence

\section{INTRODUCTION}

Bifidobacteria have been isolated from sewers [1], probiotic products [2], anaerobic digesters [3], etc., but the intestine of mammals, including humans, is considered to be their common habitat. Currently, over 40 Bifidobacterium species or subspecies are recognized [4]. In the human gut microbiota, common Bifidobacterium species include $B$. adolescentis, B. angulatum, $B$. bifidum, B. breve, B. catenulatum, B. dentium, $B$. longum, B.pseudocatenulatum, B.pseudolongum, and $B$. thermophilum $[4,5]$. Strains of these species are vaginally transmitted from mothers to infants at birth, and human milk contains oligosaccharides that can be specifically used by bifidobacteria (i.e., B. bifidum, B. breve, and $B$. longum) to become dominant members of the gut

\footnotetext{
*Corresponding author. Ro Osawa, Department of Bioresource Science, Organization of Advanced Science and Technology, Kobe University, 1-1 Rokko-dai, Nada-ku, Kobe 657-8501, Japan. Tel. \& Fax: +81-78-803-5804, E-mail: tamie@opal.kobe-u.ac.jp (C) 2017 BMFH Press

This is an open-access article distributed under the terms of the Creative Commons Attribution Non-Commercial No Derivatives (by-nc-nd) License. (CC-BY-NC-ND 4.0: https://creativecommons. org/licenses/by-nc-nd/4.0/)
}

microbiota in breast-fed infants $[6,7]$. Such evidence implies that bifidobacteria play a very important role in human health and longevity [8].

Recently, bifidobacteria from the guts of chimpanzees, which are closely related to humans and have feeding habits similar to humans, have been frequently investigated. To date, only four known Bifidobacterium species (i.e., B. angulatum, B. catenulatum, B. pseudocatenulatum, and $B$. dentium) have been identified in the guts of chimpanzees [9-11]; we speculated that like humans, chimpanzees would have a unique diversity of bifidobacteria. We herein describe the successful isolation of bifidobacteria from the feces of captive chimpanzees and clarify the taxonomic positions of these isolates.

\section{MATERIALS AND METHODS}

\section{Subject animals}

We collected fecal samples from captive chimpanzees captive at the Adventure World, Shirahama, Japan. The chimpansees included four adult females $(\mathrm{C}, \mathrm{H}, \mathrm{T}$, and $\mathrm{Y}$ ) and 2 adult males ( $\mathrm{J}$ and $\mathrm{K})$, and their ages ranged between 10 and 40 years. 
Table 1. Reference and type strains used in this study

\begin{tabular}{ll}
\hline \multicolumn{1}{c}{ Strain } & \multicolumn{1}{c}{ Origin } \\
\hline Bifidobacterium pseudolongum subsp. pseudolongum JCM 1205 & Rat feces \\
B. pseudolongum subsp. pseudolongum JCM 1264 & Mouse feces \\
B. pseudolongum subsp. pseudolongum JCM 1266 & Chicken feces \\
B. pseudolongum subsp. globosum JCM 5820 & Bovine rumen \\
B. pseudolongum subsp. globosum JCM 7089 & Bovine rumen \\
B. pseudolongum subsp. globosum JCM 7092 & Bovine rumen \\
\hline
\end{tabular}

\section{Fecal collection and sample preparation}

Fecal samples were collected in March 2015 and June 2015 and were generously provided both times by the breeding staff of Adventure World, Shirahama, Wakayama, Japan. For the first lot, a portion of fresh feces $(5-10 \mathrm{~g})$ from each chimpanzee was scooped into an appropriately labeled plastic bag immediately after defecation and kept at $-20^{\circ} \mathrm{C}$ before DNA extraction for subsequent molecular analyses. For the second lot, fresh feces (approximately $100 \mathrm{mg}$ ) from each chimpanzee were collected using commercial swabs and transport medium (BBL CultureSwab Plus, Becton Dickinson Italia, Milan, Italy), and the swabs were sent to our laboratory within 2 days before being subjected to isolation of viable bifidobacteria.

\section{Reference bacterial strains}

A total of six strains, including type or reference strains of the two subspecies of B.pseudolongum (i.e., pseudolongum and globosum), were used to help clarify the taxonomic position of the strains isolated from the chimpanzees (Table 1). Moreover, another 11 strains of 11 Bifidobacterium species were used as standards for quantitative PCR (qPCR) analysis (Table 2).

\section{DNA preparation}

Prior to DNA isolation, samples were mixed with 9 volumes of PBS. Whole genomic DNA from each fecal sample or bacterial culture was prepared following the method reported by Marmur et al. [12]. In brief, a $200-\mu l$ aliquot of each fecal solution or bacterial culture was transferred to sterile bead-beating tubes containing $300 \mathrm{mg}$ of glass beads $(0.1 \mathrm{~mm}$ in diameter). This was added to approximately $500 \mu \mathrm{l}$ of TE-saturated phenol, $250 \mu \mathrm{l}$ of lysis buffer, and $50 \mu \mathrm{l}$ of $10 \%$ sodium dodecyl sulfate. After centrifugation at $10,000 \mathrm{~g}$ for $5 \mathrm{~min}$, the upper layer was transferred to a new tube, and $400 \mu \mathrm{l}$ of phenol:chloroform:isoamyl alcohol (25:24:1) was then added to the tube and centrifuged at $10,000 \mathrm{~g}$ for $5 \mathrm{~min}$. The upper aqueous layer was carefully collected in a new tube. The samples were shaken in a FastPrep-24
Instrument (MP Biomedicals SARL, Illkirch, France) for $30 \mathrm{sec}$ at maximum speed. DNA was precipitated by adding $275 \mu \mathrm{l}$ of isopropyl alcohol and a 1/10 volume of $3 \mathrm{M}$ sodium acetate into the tube at $-20^{\circ} \mathrm{C}$ for $10-15 \mathrm{~min}$. The pellet was washed with $70 \%$ ice-cold ethanol by centrifugation at 10,000 g for $5 \mathrm{~min}$, and DNA was dried under vacuum. DNA was subsequently dissolved again in TE buffer (10 mM Tris-HCl, 1 mM EDTA, $\mathrm{pH}$ 8.0).

\section{qPCR analysis}

qPCR was performed using a Thermal Cycler Dice Real Time System (Takara Bio Inc., Ohtsu, Japan). Primer pairs targeting a part of the $16 \mathrm{~S}$ rRNA gene or the groEL gene for 12 bifidobacterial species were designed as reported by Junick et al. [4] and Matsuki et al. [13] (Table 2). For each assay, $1 \mu \mathrm{l}$ of DNA solution was added to $9 \mu \mathrm{l}$ of a PCR mixture containing $5 \mu \mathrm{l}$ of THUNDERBIRD ${ }^{\mathrm{TM}}$ SYBR $^{\circledR}$ qPCR Mix (Toyobo, Osaka, Japan), $3.6 \mu$ of distilled water, and $200 \mathrm{nM}$ of each primer. The PCR conditions for the 12 bifidobacterial species are listed in Table 3. The total number of Bifidobacterium species was quantified using the $16 \mathrm{~S}$ rRNA gene-targeted primer pair g-Bifid-F/g-Bifid-R designed as reported by Matsuki et al. [13] (Table 2).

\section{Analysis of $16 S$ rRNA gene clone libraries}

The 16S rRNA gene fragments of the Bifidobacterium species fragments in fecal samples were amplified using a conventional PCR method with the primer pair g-BifidF/g-Bifid-R (Table 2). PCR products were purified using the High Pure PCR Product Purification Kit (Roche, Basel, Switzerland) and cloned to the TA cloning site of the pGEM-T Easy Vector (Promega Benelux, Leiden, Netherlands). Resulting plasmids were introduced into Escherichia coli DH5a cells (Takara Bio Inc., Ohtsu, Japan) via heat shock. The recombinant $E$. coli strain was grown at $37^{\circ} \mathrm{C}$ in Luria-Bertani (LB) broth (Becton Dickinson and Company, Sparks, MD, USA) for $1 \mathrm{hr}$. Cultures were spread on LB agar plates containing $100 \mu \mathrm{g} / \mathrm{ml}$ ampicillin (Wako Pure Chemical Industries, Osaka, Japan) and 400 pM 5-bromo-4-chloro-3- indolyl- 


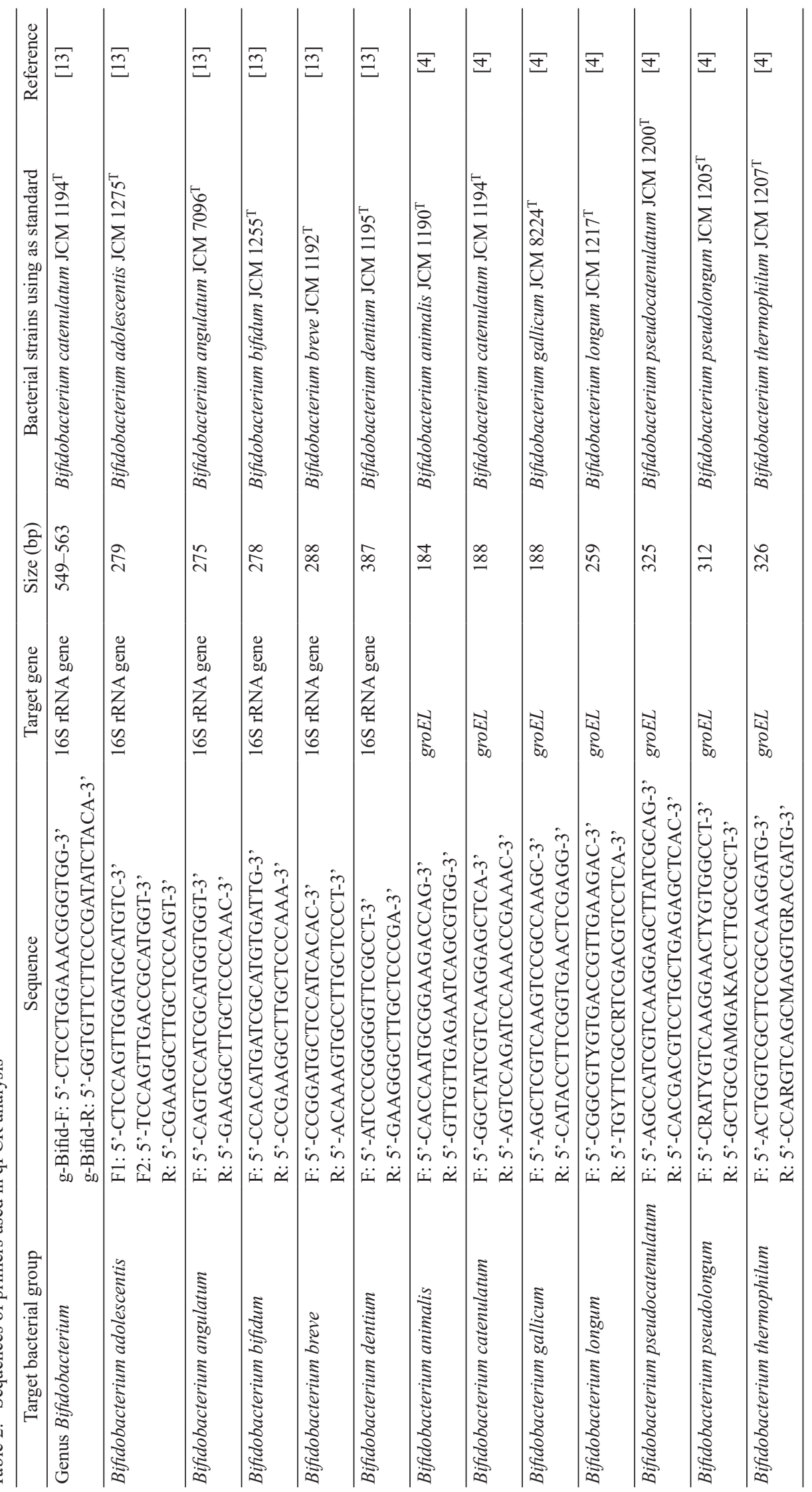


Table 3. PCR conditions of qPCR analysis

\begin{tabular}{ll}
\hline \multicolumn{1}{c}{ Target bacterial group } & PCR conditions \\
\hline Bifidobacterium & $94^{\circ} \mathrm{C}, 5 \mathrm{~min} ; 40 \mathrm{cycles}\left(94^{\circ} \mathrm{C}, 20 \mathrm{sec}, 65^{\circ} \mathrm{C}, 20 \mathrm{sec} ; 72^{\circ} \mathrm{C}, 50 \mathrm{sec}\right) ; 72^{\circ} \mathrm{C}, 10 \mathrm{~min}$ \\
Bifidobacterium adolescentis & $94^{\circ} \mathrm{C}, 5 \mathrm{~min} ; 40 \mathrm{cycles}\left(94^{\circ} \mathrm{C}, 20 \mathrm{sec}, 65^{\circ} \mathrm{C}, 20 \mathrm{sec} ; 72^{\circ} \mathrm{C}, 50 \mathrm{sec}\right) ; 72^{\circ} \mathrm{C}, 10 \mathrm{~min}$ \\
Bifidobacterium angulatum & $94^{\circ} \mathrm{C}, 5 \mathrm{~min} ; 40 \mathrm{cycles}\left(94^{\circ} \mathrm{C}, 20 \mathrm{sec}, 65^{\circ} \mathrm{C}, 20 \mathrm{sec} ; 72^{\circ} \mathrm{C}, 50 \mathrm{sec}\right) ; 72^{\circ} \mathrm{C}, 10 \mathrm{~min}$ \\
Bifidobacterium bifidum & $94^{\circ} \mathrm{C}, 5 \mathrm{~min} ; 40 \mathrm{cycles}\left(94^{\circ} \mathrm{C}, 20 \mathrm{sec}, 65^{\circ} \mathrm{C}, 20 \mathrm{sec} ; 72^{\circ} \mathrm{C}, 50 \mathrm{sec}\right) ; 72^{\circ} \mathrm{C}, 10 \mathrm{~min}$ \\
Bifidobacterium breve & $94^{\circ} \mathrm{C}, 5 \mathrm{~min} ; 40 \mathrm{cycles}\left(94^{\circ} \mathrm{C}, 20 \mathrm{sec}, 65^{\circ} \mathrm{C}, 20 \mathrm{sec} ; 72^{\circ} \mathrm{C}, 50 \mathrm{sec}\right) ; 72^{\circ} \mathrm{C}, 10 \mathrm{~min}$ \\
Bifidobacterium dentium & $94^{\circ} \mathrm{C}, 5 \mathrm{~min} ; 40 \mathrm{cycles}\left(94^{\circ} \mathrm{C}, 20 \mathrm{sec}, 65^{\circ} \mathrm{C}, 20 \mathrm{sec} ; 72^{\circ} \mathrm{C}, 50 \mathrm{sec}\right) ; 72^{\circ} \mathrm{C}, 10 \mathrm{~min}$ \\
Bifidobacterium animalis & $94^{\circ} \mathrm{C}, 3 \mathrm{~min} ; 30 \mathrm{cycles}\left(94^{\circ} \mathrm{C}, 30 \mathrm{sec}, 65^{\circ} \mathrm{C}, 30 \mathrm{sec} ; 72^{\circ} \mathrm{C}, 30 \mathrm{sec}\right) ; 72^{\circ} \mathrm{C}, 10 \mathrm{~min}$ \\
Bifidobacterium catenulatum & $94^{\circ} \mathrm{C}, 3 \mathrm{~min} ; 30 \mathrm{cycles}\left(94^{\circ} \mathrm{C}, 30 \mathrm{sec}, 47^{\circ} \mathrm{C}, 30 \mathrm{sec}, 72^{\circ} \mathrm{C}, 30 \mathrm{sec}\right) ; 72^{\circ} \mathrm{C}, 10 \mathrm{~min}$ \\
Bifidobacterium gallicum & $94^{\circ} \mathrm{C}, 3 \mathrm{~min} ; 30 \mathrm{cycles}\left(94^{\circ} \mathrm{C}, 30 \mathrm{sec}, 57^{\circ} \mathrm{C}, 30 \mathrm{sec}, 72^{\circ} \mathrm{C}, 30 \mathrm{sec}\right) ; 72^{\circ} \mathrm{C}, 10 \mathrm{~min}$ \\
Bifidobacterium longum & $94^{\circ} \mathrm{C}, 3 \mathrm{~min} ; 30 \mathrm{cycles}\left(94^{\circ} \mathrm{C}, 30 \mathrm{sec} ; 66^{\circ} \mathrm{C}, 30 \mathrm{sec}, 72^{\circ} \mathrm{C}, 30 \mathrm{sec}\right) ; 72^{\circ} \mathrm{C}, 10 \mathrm{~min}$ \\
Bifidobacterium pseudocatenulatum & $94^{\circ} \mathrm{C}, 3 \mathrm{~min} ; 30 \mathrm{cycles}\left(94^{\circ} \mathrm{C}, 50 \mathrm{sec}, 64^{\circ} \mathrm{C}, 50 \mathrm{sec}, 72^{\circ} \mathrm{C}, 50 \mathrm{sec}\right) ; 72^{\circ} \mathrm{C}, 10 \mathrm{~min}$ \\
Bifidobacterium pseudolongum & $94^{\circ} \mathrm{C}, 3 \mathrm{~min} ; 30 \mathrm{cycles}\left(94^{\circ} \mathrm{C}, 30 \mathrm{sec}, 49^{\circ} \mathrm{C}, 30 \mathrm{sec}, 72^{\circ} \mathrm{C}, 30 \mathrm{sec}\right) ; 72^{\circ} \mathrm{C}, 10 \mathrm{~min}$ \\
Bifidobacterium thermophilum & $94^{\circ} \mathrm{C}, 3 \mathrm{~min} ; 30 \mathrm{cycles}\left(94^{\circ} \mathrm{C}, 40 \mathrm{sec}, 65^{\circ} \mathrm{C}, 40 \mathrm{sec}, 72^{\circ} \mathrm{C}, 40 \mathrm{sec}\right) ; 72^{\circ} \mathrm{C}, 10 \mathrm{~min}$ \\
\hline
\end{tabular}

$\beta$-D-galactopyranoside (Sigma-Aldrich, St, Louis, MO, USA) and grown overnight at $37^{\circ} \mathrm{C}$. White colonies were subcultured to new LB agar plates using an autoclaved toothpick and then incubated at $37^{\circ} \mathrm{C}$ for $16 \mathrm{hr}$.

At least 10 colonies were selected from each library and then grown overnight in LB broth. Plasmids were harvested and purified from the overnight cultures using a plasmidPrep Mini Spin Kit (GE Healthcare UK Limited, Little Chalfont, Buckinghamshire, UK). Sequencing of inserted fragments was performed with the vector-specific primers T7 (5'-TAATACGACTCACTATAGGG-3') and SP6 (5'-CAAGCTATTTAGGTGACACTATAG-3') using a BigDye Terminator v3.1 Cycle Sequencing Ready Reaction kit (Applied Biosystems, Warrington, UK) and Applied Biosystems 3100xl Genetic Analyzer (Applied Biosystems, Darmstadt, Germany).

\section{Isolation of tentatively bifidobacterial strains from chimpanzee feces}

Fresh feces of six chimpanzees were serially diluted with $1 \times \mathrm{PBS}$ and streaked on TOS propionate (Yakult, Tokyo, Japan) and BL (Nissui Pharmaceutical, Tokyo, Japan) agar plates with platinum loops. The agar plates were then anaerobically incubated (Mitsubishi Gas Chemical Company, Tokyo, Japan) at $37^{\circ} \mathrm{C}$ for $48 \mathrm{hr}$. Well isolated colonies that appeared to be bifidobacteria were tentatively identified as Bifidobacterium strains for further taxonomic analyses as described below.

\section{PCR amplification and 16S rRNA sequencing of isolates}

A large, continuous fragment (approximately $1440 \mathrm{bp}$ ) of the $16 \mathrm{~S}$ rRNA gene from isolates was obtained using universal primers $27 \mathrm{~F}$
(5'-AGAGTTTGATCMTGGCTCAG-3') and 1492R (5'-TACGGYTACCTTGTTACGACTT-3'). PCR products were purified using a NucleoSpin Extract II Kit (Macherey-Nagel, Duren, Germany). Sequencing was performed with the primers 27F, 518F (5'-CCAGCAGCCGCGGTAATACG-3'), 1100R (5'-GGGTTGCGCTCGTTG-3'), and 1492R using a BigDye Terminator v3.1 Cycle Sequencing Ready Reaction Kit (Applied Biosystems) and Applied Biosystems 3100xl Genetic Analyzer (Applied Biosystems).

\section{PCR amplification and sequencing of groEL}

A large, continuous fragment (approximately $1600 \mathrm{bp}$ ) of the groEL gene from our isolates was obtained using the primers BpgroF (5'-TCATTGAATATGATGAGGAAGCA-3') and BpgroR (5'-AACAGCCTCGGTCGTCAG-3'), which were designed for amplification of the B. pseudolongum groEL gene based on the complete genome sequence B. pseudolongum PV-8 (accession number CP007457.1) [15]. Amplification reactions were performed using the following program: $94^{\circ} \mathrm{C}$ for $5 \mathrm{~min}$, followed by 40 cycles of $94^{\circ} \mathrm{C}$ for $30 \mathrm{sec}, 55^{\circ} \mathrm{C}$ for $30 \mathrm{sec}$, and $72^{\circ} \mathrm{C}$ for $90 \mathrm{sec}$, with a final extension period at $72^{\circ} \mathrm{C}$ for $10 \mathrm{~min}$. PCR products were then purified using a NucleoSpin Extract II Kit (Macherey-Nagel, Duren, Germany). Sequencing of the purified PCR products was performed with the same primers as used for PCR using the BigDye Terminator v3.1 Cycle Sequencing Ready Reaction Kit (Applied Biosystems, Warrington, UK) and Applied Biosystems 3100xl Genetic Analyzer (Applied Biosystems, Darmstadt, Germany). 
Table 4. Quantification of Bifidobacteirum species in feces of captive chimpanzees

\begin{tabular}{|c|c|c|c|c|c|c|c|}
\hline \multirow{2}{*}{ Target gene } & \multirow{2}{*}{ Target species } & \multicolumn{6}{|c|}{ Individual chimpanzees* } \\
\hline & & $\mathrm{H}$ & $\mathrm{C}$ & $\mathrm{J}$ & $\mathrm{Y}$ & $\mathrm{T}$ & $\mathrm{K}$ \\
\hline \multirow[t]{6}{*}{ 16S rRNA gene } & Total Bifidobacterium & 8.89 & 8.58 & 7.49 & 9.87 & 10.26 & 7.58 \\
\hline & B. adolescentis & - & - & - & - & - & - \\
\hline & B. angulatum & - & - & - & - & - & - \\
\hline & B. bifidum & - & - & - & - & - & - \\
\hline & B. breve & - & - & - & - & - & - \\
\hline & B. dentium & - & - & - & - & - & - \\
\hline \multirow[t]{7}{*}{ groEL } & B. animalis & - & - & - & - & - & - \\
\hline & B. catenulatum & - & - & - & - & - & - \\
\hline & B. gallicum & - & - & - & - & - & - \\
\hline & B. longum & - & - & - & - & - & - \\
\hline & B. pseudocatenulatum & - & - & - & 8.16 & - & - \\
\hline & B. pseudolongum & - & - & - & - & 6.80 & - \\
\hline & B. thermophilum & - & - & - & - & - & - \\
\hline
\end{tabular}

*Values indicate the $\log _{10}$ cells/g in fecal samples.

A dash (-) indicates that the value was less than the detection limit.

\section{Phylogenetic analysis}

Obtained 16S rRNA and groEL sequences were aligned via ClustalW using the MEGA5 software package [16]. Sequences were subjected to similarity search analysis using the BLAST algorithm in the NCBI database. Phylogenetic trees based on groEL sequences were constructed using the neighbor-joining method [17] with MEGA5. Other phylogenetically related Bifidobacterium groEL sequences retrieved from GenBank were also included. The stability of the groupings was estimated via bootstrap analysis (1,000 replications).

\section{Whole genome sequences of isolates}

Whole genome sequences of 3 of our isolates (T$1, \mathrm{~J}-1$, and $\mathrm{Y}-1$ ) were determined using the Illumina/ Solexa technology. An average of $0.75-3.38$ million paired-end reads of $262.1 \mathrm{bp}$ were generated by MiSeq (Illumina, San Diego, CA, USA). All generated reads were assembled into contigs using the CLC Genomics Workbench software v. 6.0 (CLC bio, Aarhus, Denmark).

\section{Calculation of average nucleotide identity (ANI) values}

The degree of pairwise genome-based relatedness was calculated as an ANI value following the BLAST-based ANI calculation method using the JSpecies software [18]. ANI values for Bifidobacterium strains, including those designated to B.pseudolongum, whose genome sequences were available in the GenBank database were calculated.

\section{Biochemical characterization}

Physiological and biochemical characteristics of isolates were determined with commercially available identification kits, API 20A and Rapid ID 32A (bioMérieux, Lyon, France), according to manufacturer's protocols.

\section{Nucleotide sequence accession number}

The determined sequences of the groEL gene and $16 \mathrm{~S}$ rRNA gene of the isolates from the captive chimpanzees were completely identical. The GenBank/EMBL/DDBJ accession numbers for the $16 \mathrm{~S}$ rRNA and groEL gene sequences of strain T-1 are LC210630 and LC210631, respectively. The GenBank/EMBL/DDBJ BioProject ID for the draft genome sequences of strains $\mathrm{T}-1, \mathrm{~J}-1$, and $\mathrm{Y}-1$ is PRJDB5473.

\section{RESULTS}

\section{Quantification of Bifidobacterium species in chimpanzee} fecal samples

The number of Bifidobacterium species in $1 \mathrm{~g}$ chimpanzee feces was quantified via $\mathrm{qPCR}$, and the detection limit was taken as $1 \times 10^{5}$ cells $/ \mathrm{g}$. Although more than $3.1 \times 10^{7}$ cells $/ g$ of Bifidobacterium was detected in all fecal samples, B.pseudocatenulatum and B.pseudolongum were detected in the feces of chimpanzee $\mathrm{Y}\left(1.4 \times 10^{8}\right.$ cells $/ \mathrm{g}$ for the groEL sequence $)$ and chimpanzee $\mathrm{T}\left(1.5 \times 10^{6}\right.$ cells/g for the groEL sequence), respectively (Table 4). No other species were detected from the fecal samples. Although a certain number of Bifidobacterium species were detected all together in genus-specific qPCR, species-specific qPCR could not detect as many bifidobacterial species (Table 4). 
Analysis of $16 \mathrm{~S} r R N A$ gene clone libraries

To investigate a cause for the numerical difference between the total number of Bifidobacterium and bifidobacterial species in chimpanzee fecal samples, we performed a 16S rRNA gene clone library analysis. More than 60 clones were sequenced. The obtained sequences were subjected to a similarity search analysis using the BLAST algorithm in the NCBI database. Comparative 16S rRNA gene sequence analysis revealed 99-100\% sequence similarities between all clones and B. pseudolongum subsp. pseudolongum JCM $1205^{\mathrm{T}}$, and the clones and B. pseudomlongum subsp. pseudolongum JCM $1205^{\mathrm{T}}$ formed a cluster independently from other closely related species.

\section{Isolation and identification of bifidobacterial strains from chimpanzee feces}

A total of seven bifidobacterial strains ( $\mathrm{H}-1, \mathrm{H}-2, \mathrm{~T}-1$, $\mathrm{T}-2, \mathrm{~J}-1, \mathrm{C}-1$, and $\mathrm{Y}-1$ ) were obtained from five of the chimpanzees (C, H, J, T, and Y). Approximately 1350 $\mathrm{bp}$ of the 16S rRNA gene sequence of each isolate was determined and then compared with published sequences obtained from GenBank nucleotide databases using the BLAST algorithm. Because our phylogenetic analysis based on 16S rRNA gene sequences showed that all the strains possessed high sequence similarities (99.5\%) to B. pseudolongum subsp. pseudolongum JCM $1205^{\mathrm{T}}$, the isolates were tentatively identified as B. pseudolongum.

\section{GroEL sequence analysis}

The 16S rRNA gene has been widely used as a valuable tool for bacterial identification [13]. However, the resolution power of the 16S rRNA gene among closely related species is limited. Some Bifidobacterium species reveal a relatively high $16 \mathrm{~S}$ rRNA gene sequence identity [13]. The groEL gene has been previously used to differentiate Bifidobacterium species [4, 13]. Thus, we designed primers targeting the groEL gene of $B$. pseudolongum based on the complete genome sequence of B. pseudolongum PV-8. Approximately $1,450 \mathrm{bp}$ of the groEL gene of each isolate was determined, and all the sequences were completely identical.

Comparative sequence analysis revealed 95.6-98.6\% sequence similarities for groEL between our isolates and known B.pseudolongum strains, including B. pseudolongum subsp. pseudolongum JCM $1205^{\mathrm{T}}$ (98.6\% of sequence identity) and B.pseudolongum subsp. globosum JCM $5820^{\mathrm{T}}$ (95.6\% of sequence identity). Such results demonstrated their high genetic relatedness, but we also observed marked differences from those of other Bifidobacterium species, i.e., less than $87.7 \%$ sequence similarities. Moreover, these isolates and B. pseudolongum subsp. pseudolongum JCM $1205^{\mathrm{T}}$ formed one cluster among Streptococcus species in phylogenetic trees inferred from groEL sequence comparisons (Fig. 1).

\section{Whole genome sequence analysis}

To further elucidate the taxonomic position of isolates obtained from chimpanzee feces, draft genome sequences were generated. Whole genome sequences of strains T-1, $\mathrm{J}-1$, and Y-1 were determined using Illumina MiSeq technology. An average of 0.75-3.38 million paired-end reads, with a length of $262.1 \mathrm{bp}$, were generated via the MiSeq system. The resulting draft genomes of the three isolates had 11 or 12 contigs with $200-1,000$-fold coverage, and the genome size ranged from 1.94 to 1.95 $\mathrm{Mb}$. The degree of pairwise genome-based relatedness was calculated as the ANI value according to the BLASTbased ANI calculation method. The ANI values among isolates, $\mathrm{T}-1, \mathrm{~J}-1$, and $\mathrm{Y}-1$ and the strain $B$. pseudolongum subsp. pseudolongum JCM $1205^{\mathrm{T}}$ ranged from $98.6 \%$ to $99.9 \%$ (Table 5). These ANI values were higher than the $95 \%$ ANI cut-off value for bacterial species proposed by Goris et al. [19]. On the other hand, the ANI values between our isolates and B. pseudolongum subsp. globosum JCM $5820^{\mathrm{T}}$ were closer (95.5\%) to the proposed ANI cut-off value for bacterial species (Table $5)$.

\section{Biochemical characterization}

The differential biochemical characteristics among the strains used in this study are shown in Table 6. Based on analyses with the API 20A and Rapid ID 32A systems, our isolates, JCM 1264, JCM 7089, and JCM 7092, possessed similar carbohydrate fermentation patterns, with the exception of the strain C-1. Strain C-1 possessed similar carbohydrate fermentation patterns similar to those of B.pseudolongum subsp. pseudolongum JCM $1205^{\mathrm{T}}$ [20]. Combining groEL phylogeny, genome sequence comparative analysis, and carbohydrate fermentation patterns, we concluded that our J1, T1 and Y1 isolates were B. pseudolongum subsp. pseudolongum and that the other strains were also identical or closely related to this subspecies.

\section{DISCUSSION}

Bifidobacteria are known to establish a balance in the gut microbiota and confer health benefits to the host. They represent one of the largest bacterial groups within Actinobacteria, and most Bifidobacterium 


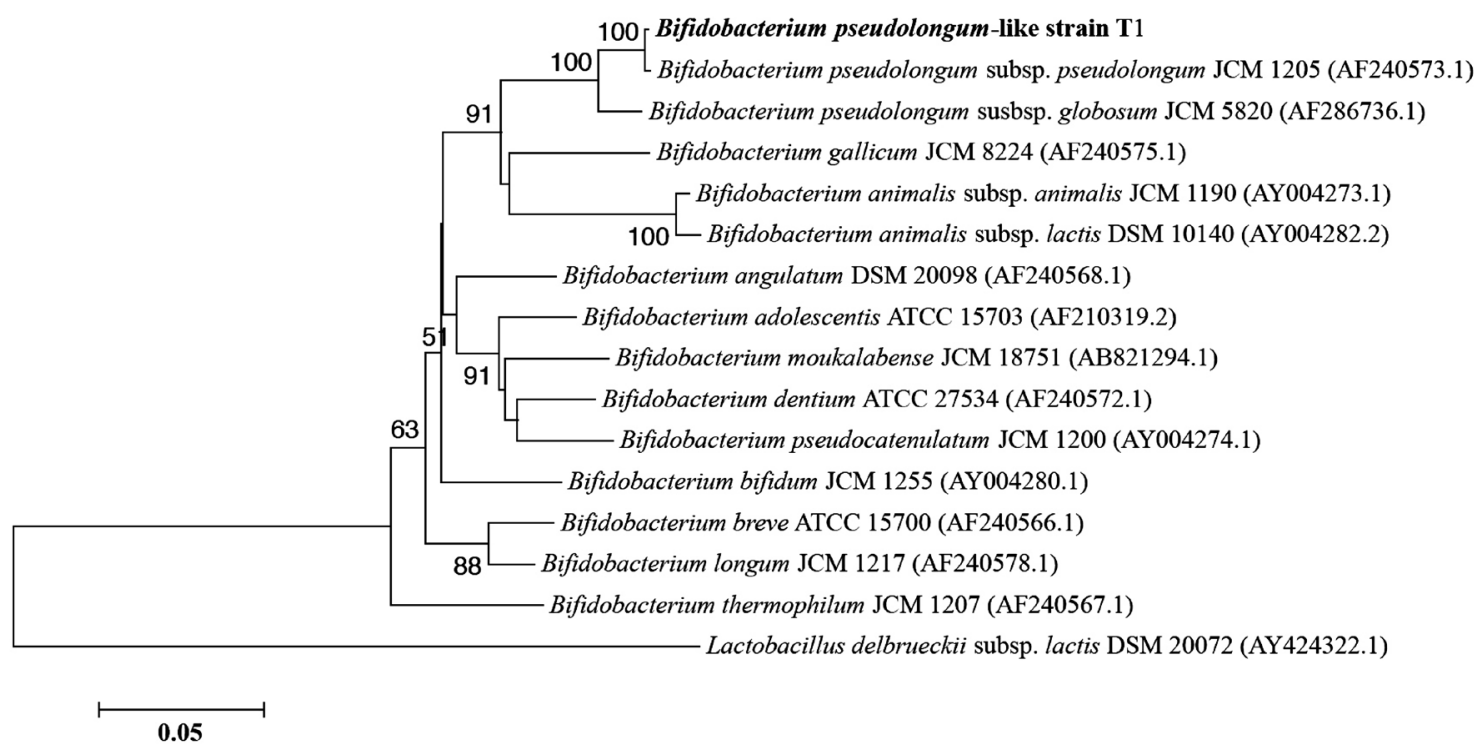

Fig. 1. The groEL gene sequence-based phylogenetic tree of Bifidobacterium pseudolongum-like strain T1 and selected type strains of species of the genus Bifidobacterium.

The neighbor-joining tree is shown here with bootstrap support values; only values $>50 \%$ are shown. Bar, $5 \%$ sequence divergence. Accession numbers of the reference sequences used in the phylogenetic analysis are shown in parentheses. Lactobacillus delbrueckii is shown as an outgroup.

Table 5. Average nucleotide identity (ANI) values among the genome sequences of genus Bifidobacteirum

\begin{tabular}{|c|c|c|c|c|c|c|c|}
\hline Strain names & PV8-2 & $\mathrm{J}-1$ & $\mathrm{~T}-1$ & Y-1 & $\begin{array}{c}\text { JCM } \\
1205^{\mathrm{T}}\end{array}$ & $\begin{array}{c}\text { JCM } \\
5820^{\mathrm{T}}\end{array}$ & $\begin{array}{c}\text { JCM } \\
1190^{\mathrm{T}}\end{array}$ \\
\hline B. pseudolongum PV8-2 (CP007457) & --- & 93.82 & 93.81 & 93.82 & 93.45 & 95.79 & 86.01 \\
\hline $\mathrm{J}-1$ & & --- & 99.9 & 99.91 & 98.62 & 95.52 & 86.93 \\
\hline $\mathrm{T}-1$ & & & --- & 99.94 & 98.61 & 95.52 & 86.87 \\
\hline Y-1 & & & & --- & 98.63 & 95.53 & 86.89 \\
\hline B. pseudolongum subsp. pseudolongum JCM1205 (NZ_JGZH01000001-11) & & & & & --- & 94.75 & 86.13 \\
\hline B. pseudolongum subsp. globsum JCM5820 (NZ_JGZG01000001-26) & & & & & & --- & 87.04 \\
\hline B. animalis $\mathrm{JCM} 1190^{\mathrm{T}}(\mathrm{CP} 002567)$ & & & & & & & --- \\
\hline
\end{tabular}

*Bold: $>98 \%$, The DDBJ/EMBL/GenBank accession numbers of reference and type strains are given in parenthese.

species are found in the gastrointestinal tract of humans and animals and in the hindgut of insects. However, little information is available regarding the intestinal microbiota of chimpanzees. Recently, limited sequence analyses and isolation experiments suggested the presence of B. catenulatum-, B.pseudocatenulatum-, and $B$. angulatum-like species in wild chimpanzees from Bossou, Guinea $[9,10]$. In this study, we successfully isolated the B.pseudolongum subsp. pseudolongum strains from the feces of chimpanzees living in captivity. B. pseudolongum comprises two subspecies, pseudolongum and globosum, and is often detected in the feces of various animals, such as rats, pigs, sheep, cows [20], dogs, and cheetahs [11]. With respect to primates, B. pseudolongum has only been isolated from humans $[4,14]$. To the best of our knowledge, this is the first report of B.pseudolongum being identified in a nonhuman primate species. Thus, our findings indicated the possibility of chimpanzees possessing a unique diversity of bifidobacteria. Via 16S rRNA gene clone library analysis, all analyzed clones were shown to have possessed $16 \mathrm{~S}$ rRNA fragments highly identical to B. pseudolongum. Thus, B. pseudolongum may be predominant in the intestinal bifidobacterial flora of these chimpanzees.

In this study, we also assessed the groEL gene. This housekeeping gene undergoes mutation more easily than 16S rRNA, which may help in differentiating 
Table 6. Characteristics that differentiate among the strains used in this study

\begin{tabular}{|c|c|c|c|c|c|c|c|c|c|c|c|c|c|}
\hline & 1 & 2 & 3 & 4 & 5 & 6 & 7 & 8 & 9 & 10 & 11 & 12 & 13 \\
\hline Hydrolysis of arginine & - & - & - & - & - & + & + & - & + & - & + & - & + \\
\hline Hydrolysis of esculin & - & + & - & + & + & + & + & + & + & + & + & - & + \\
\hline \multicolumn{14}{|l|}{ Production of (ID 32A) of } \\
\hline$\beta$-Glucosidase & $\mathrm{nt}$ & + & + & - & + & - & - & - & + & - & + & - & + \\
\hline$\beta$-Galactosidase & $\mathrm{nt}$ & + & + & + & + & + & - & + & + & + & + & + & + \\
\hline$\alpha$-Glucosidase & $\mathrm{nt}$ & - & + & + & + & + & - & - & - & + & - & + & - \\
\hline$\alpha$-Galactosidase & $\mathrm{nt}$ & + & + & + & - & - & - & + & - & + & - & + & - \\
\hline$\alpha$-Arabinosidase & nt & - & + & - & - & - & - & + & - & + & - & + & - \\
\hline Proline arylamidase & $\mathrm{nt}$ & + & + & + & + & + & + & + & - & + & - & + & - \\
\hline Pyroglutamic acid arylamidase & $\mathrm{nt}$ & - & - & - & + & + & + & - & + & - & + & - & + \\
\hline Argininec arylamidase & $\mathrm{nt}$ & + & + & + & + & + & + & - & + & - & + & + & + \\
\hline Alanine arylamidase & $\mathrm{nt}$ & - & + & - & + & + & + & - & + & + & + & - & - \\
\hline \multicolumn{14}{|l|}{ Production (API 20A) of acid from } \\
\hline Salicin & + & + & + & + & + & + & + & + & + & + & + & - & + \\
\hline Mannitol & - & + & - & + & + & + & + & + & + & + & + & - & + \\
\hline Xylose & + & - & - & + & - & - & - & + & - & - & + & + & - \\
\hline Cellobiose & - & + & - & + & + & + & + & + & + & + & + & - & + \\
\hline Raffinose & + & - & + & + & - & - & - & + & - & - & - & + & - \\
\hline Mannose & - & + & + & + & + & + & + & + & + & + & + & - & + \\
\hline Trehalose & - & + & - & + & + & + & + & + & + & + & + & - & + \\
\hline
\end{tabular}

Strains: 1, B. pseudolongum subsp. pseudolongum JCM 1205' ; , B. pseudolongum subsp. pseudolongum JCM 1264; 3, B. pseudolongum subsp. pseudolongum JCM 1266; 4, B. pseudolongum subsp. globsum JCM 5820 ${ }^{\mathrm{T}}$; 5, B. pseudolongum subsp. globsum JCM 7089; 6, B. pseudolongum subsp. globsum JCM 7092; 7, H-1; 8, H-2; 9, T-1; 10, T-2; 11, J-1; 12, C-1; 13, Y-1.

Phenotypic data for strains 2 to 13 are from this study. Data for strain 1 are from Yaeshima et al. [20]. +, positive reaction;-, negative reaction; nt, not tested.

between species [15]. Via our qPCR analysis of groEL, B. pseudolongum was not detected in the feces of the captive chimpanzees, although B.pseudolongum was the predominant species detected according to our clone library analysis. The sequence analysis of the groEL gene revealed that there is a nucleotide mutational point near the 3 '-end of the B. pseudolongum-specific primers used in this study. This mutation site might have inhibited the qPCR extension step in our analysis. We presumed that this is the reason why B.pseudolongum was not detected via qPCR using our primers targeting groEL. Thus, we designed primers that could specifically amplify the partial sequence of the 16S rRNA gene of B. pseudolongum and B. animalis and re-performed the qPCR analysis. The bifidobacterial cell numbers based on this qPCR analysis were comparable to the total cell numbers of Bifidobacterium species in five samples (data not shown). At the moment, the distribution and role of B. pseudolongum in captive chimpanzees is unclear, although bifidobacteria are believed to be a common member of the chimpanzee intestinal microbiota [10]. Further study is required to clarify the unique diversity of bifidobacterial flora in chimpanzees.

\section{ACKNOWLEDGEMENTS}

After the preparation of this paper, Dr. Hiroshi Kusunoki, a co-author of this paper, passed away, and we extend our sincerest condolences to his family, friends, and colleagues. We sincerely appreciate his dedication to our research and hope his soul rests in peace. We are also grateful to Adventure World AWS Co. Ltd. for their generous provision of fecal samples from their captive chimpanzees. There are no commercial or other associations that might pose as conflicts of interest with respect to the submitted manuscript.

\section{REFERENCES}

1. Scardovi V, Trovatelli LD. 1974. Bifidobacterium animalis (Mitsuoka) comb. nov. and the "minimum" and "subtile" group of new bifidobacteria found in sewage. Int J Syst Bacteriol 24: 21-28. [CrossRef]

2. Watanabe K, Makino H, Sasamoto M, Kudo Y, Fujimoto J, Demberel S. 2009. Bifidobacterium mongoliense sp. nov., from airag, a traditional fermented mare's milk product from Mongolia. Int J Syst Evol Microbiol 59: 1535-1540. [Medline] [CrossRef]

3. Dong X, Xin Y, Jian W, Liu X, Ling D. 2000. Bifidobacterium thermacidophilum $\mathrm{sp}$. nov., isolated 
from an anaerobic digester. Int J Syst Evol Microbiol 50: 119-125. [Medline] [CrossRef]

4. Junick J, Blaut M. 2012. Quantification of human fecal bifidobacterium species by use of quantitative real-time PCR analysis targeting the groEL gene. Appl Environ Microbiol 78: 2613-2622. [Medline] [CrossRef]

5. von Ah U, Mozzetti V, Lacroix C, Kheadr EE, Fliss I, Meile L. 2007. Classification of a moderately oxygentolerant isolate from baby faeces as Bifidobacterium thermophilum. BMC Microbiol 7: 79. [Medline] [CrossRef]

6. Makino H, Kushiro A, Ishikawa E, Kubota H, Gawad A, Sakai T, Oishi K, Martin R, Ben-Amor K, Knol J, Tanaka R. 2013. Mother-to-infant transmission of intestinal bifidobacterial strains has an impact on the early development of vaginally delivered infant's microbiota. PLoS One 8: e78331. [Medline] [CrossRef]

7. Zivkovic AM, German JB, Lebrilla CB, Mills DA. 2011. Human milk glycobiome and its impact on the infant gastrointestinal microbiota. Proc Natl Acad Sci USA 108 Suppl 1: 4653-4658. [Medline] [CrossRef]

8. Mitsuoka T. 2014. Establishment of intestinal bacteriology. Biosci Microbiota Food Health 33: 99-116. [Medline] [CrossRef]

9. Ushida K, Uwatoko $Y$, Adachi $Y$, Soumah AG, Matsuzawa T. 2010. Isolation of Bifidobacteria from feces of chimpanzees in the wild. J Gen Appl Microbiol 56: 57-60. [Medline] [CrossRef]

10. Uenishi G, Fujita S, Ohashi G, Kato A, Yamauchi S, Matsuzawa T, Ushida K. 2007. Molecular analyses of the intestinal microbiota of chimpanzees in the wild and in captivity. Am J Primatol 69: 367-376. [Medline] [CrossRef]

11. D'Aimmo MR, Modesto M, Mattarelli P, Biavati B, Andlid T. 2014. Biosynthesis and cellular content of folate in bifidobacteria across host species with different diets. Anaerobe 30: 169-177. [Medline] [CrossRef]

12. Marmur J. 1961. A procedure for the isolation of deoxyribonucleic acid from micro-organisms. J Mol
Biol 3: 208-218. [CrossRef]

13. Matsuki T, Watanabe K, Fujimoto J, Kado Y, Takada T, Matsumoto K, Tanaka R. 2004. Quantitative PCR with 16S rRNA-gene-targeted species-specific primers for analysis of human intestinal bifidobacteria. Appl Environ Microbiol 70: 167-173. [Medline] [CrossRef]

14. Vazquez-Gutierrez P, Lacroix C, Chassard C, Klumpp J, Stevens MJ, Jans C. 2015. Bifidobacterium pseudolongum strain PV8-2, isolated from a stool sample of an anemic Kenyan infant. Genome Announc 3: e01469-e14. [Medline]

15. Wong RS, Chow AW. 2002. Identification of enteric pathogens by heat shock protein $60 \mathrm{kDa}$ (HSP60) gene sequences. FEMS Microbiol Lett 206: 107-113. [Medline] [CrossRef]

16. Tamura K, Peterson D, Peterson N, Stecher G, Nei M, Kumar S. 2011. MEGA5: molecular evolutionary genetics analysis using maximum likelihood, evolutionary distance, and maximum parsimony methods. Mol Biol Evol 28: 2731-2739. [Medline] [CrossRef]

17. Saitou N, Nei M. 1987. The neighbor-joining method: a new method for reconstructing phylogenetic trees. Mol Biol Evol 4: 406-425. [Medline]

18. Richter M, Rosselló-Móra R. 2009. Shifting the genomic gold standard for the prokaryotic species definition. Proc Natl Acad Sci USA 106: 19126-19131. [Medline] [CrossRef]

19. Goris J, Konstantinidis KT, Klappenbach JA, Coenye T, Vandamme P, Tiedje JM. 2007. DNADNA hybridization values and their relationship to whole-genome sequence similarities. Int J Syst Evol Microbiol 57: 81-91. [Medline] [CrossRef]

20. Yaeshima T, Fujisawa T, Mitsuoka T. 1992. Bifidobacterium globosum, subjective synonym of Bifidobacterium pseudolongum, and description of Bifidobacterium pseudolongum subsp. pseudolongum comb. nov. and Bifidobacterium pseudolongum subsp. globosum comb. nov. Syst Appl Microbiol 15: 380385. [CrossRef] 